perspoctive cirad

\title{
Control of zoonotic diseases The contribution in Africa and Asia of research to One Health
} François ROGER

Zoonotic diseases cause 2.2 million deaths and 2.4 billion cases of human illness throughout the world. They are concentrated in lowand middle-income countries in Asia and Africa, but the whole world is at risk of a potential pandemic.

To combat these diseases, the international organisations are promoting the One Health concept, which is aimed at jointly addressing human health, animal health and the environment. However, the implementation of this approach is encountering numerous technical, scientific and institutional difficulties.

Research will facilitate this implementation. This is shown by the interdisciplinary research conducted in Africa and Asia, associating methods used in the fields of human health and animal health, as well as the different stakeholders within these sectors. The promising findings of this research are helping to define the content of the concept and prefigure the management of the One Health initiative.

Zoonotic diseases, which can be transmitted from domestic and wild animals to humans as well as from humans to animals, cause 2.2 million deaths and 2.4 billion cases of human illness every year in the world. They represent $60 \%$ of human infectious diseases and $75 \%$ of emerging diseases (Grace D. et al., 2012).

perspactive

Through Perspective CIRAD provides the opportunity to explore new avenues for discussion and action based on research and expertise, without presenting an institutional position.
Many zoonoses are concentrated in low- or middle-income countries in Africa and Asia, but the risk of pandemic exists at the global level: a new virus strain (of influenza, for example) could emerge from an animal and be transmitted to humans; or a virus hosted by animals (such as bats or rodents) could be transmitted to humans. It is therefore important to target high-risk countries.

The international organisations are promoting the One Health concept. This concept is well suited to countries with limited resources for combating zoonoses as well as exclusively animal diseases with potentially serious indirect consequences for human health and the economy. Launched in 2008, the One Health initiative is based on the following premise: in an interconnected world that is undergoing considerable climate and environmental change, human, animal and environmental health are inextricably linked. It advocates 
The One Health concept is difficult

to implement:

researchers, public

authorities and

operators are often

locked into their own

discipline or field of

action.

Research can act as a facilitator, as shown by the work of CIRAD's AGIRs research unit and its partners (see box p.4). This research focuses on the following areas: the ecology of pathogens borne by small mammals (bats and rodents) in Central Africa and Southeast Asia; the epidemiology of diseases, such as influenza in Southeast Asia, or cryptosporidiosis in Southern Africa; and the optimisation of monitoring and surveillance systems. This research is original in that it implements the recommendations of the One Health concept: connecting several disciplines (epidemiology, ecology, microbiology, parasitology and, more recently, human and social science); combining methods used in both animal and human health; associating stakeholders from both sectors; and setting up training programmes.

\section{Connecting several disciplines}

In the forests of Gabon, wildlife ecologists are studying the behaviour of bats, and medical microbiologists are searching for pathogens that are potentially harmful to humans. In Southeast Asia, parasitologists from human and veterinary medicine are identifying rodent-borne pathogens that are transmissible to humans; and ecologists and geographers are studying their environment. But isolating a parasite or a virus in a bat or a rodent does not necessarily mean that this pathogen will emerge in humans and cause an epidemic. Modelling studies (probabilistic risk assessment) associating human medicine, veterinary medicine and environmental science are identifying the dangers at the human-animal interface and proposing preventive measures.

The study of cryptosporidiosis, a serious intestinal disease shared by animals (mammals and birds) and human populations, has brought together in Southern Africa researchers from several disciplines. Veterinary and medical doctors have worked together to develop protocols, and have then conducted surveys and taken samples among animal and human populations. Molecular biologists, ecologists and epidemiologists have analysed the data and put into perspective the results concerning the pathogens, their possible ecology and their potential transmission between species. Thanks to the global approach thus implemented, the existence of strains of cryptosporidiosis shared by animals and humans has been demonstrated. The transmission of this parasite between wild animals, domestic animals and humans is a potential risk for human populations that are immunocompromised due to other infections (HIV). Research must be pursued in order to propose methods to control this parasitic disease: this will associate sociology (risk perception, hygiene), economics (the cost for the community, etc.), and ecology (movements of animals, contact networks between species, etc.).

New research questions are emerging, which require the contribution of ecology and human and social science: for example, the role of the environment on health, whether positive (ecosystem services for disease regulation) or negative (biodiversity loss, environmental degradation, and exposure of humans and domestic animals to new pathogens).

Ecology and human and social science will need to be systematically associated in the study of zoonoses in order to accurately describe the impact and perception of diseases, to understand behaviour that facilitates their transmission, and to compare "before and after" and "here and elsewhere" situations. Health geography will also have a key role to play in One Health research. Indeed, this scientific field provides new frameworks by mobilising other disciplines from life science and human and social science. These disciplines, which study social ecosystems as a whole, also help to bring the different sectors closer together.

\section{Bringing sectors together and associating stakeholders}

The intersectoral approach is another characteristic of One Health research.

To create links between veterinary medicine and human medicine, epidemiology acts as a catalyst. Its goal is the same whatever the sector: better understanding diseases in their systemic dimension in order to target monitoring and surveillance and thereby improve health. The methods used are also the same: studying humans and animals under real con- 
Participatory

approaches are

being implemented

as alternative or

complementary

methods.

\section{FIND OUT MORE}

Atlas RM, 2012. One Health: Its Origins and Future. Curr Top Microbiol Immunol. DOI: 10.1007/82_2012_223.

Grace D. et al., 2012. Mapping of poverty and likely zoonoses hotspots: Report to the Department for International Development. Nairobi, Kenya: ILRI.

Zinsstag J. et al., 2005. Potential of cooperation between human and animal health to strengthen health systems. Lancet. 17 Dec; 366 (9503): 2142-5. ditions of exposure to biological, behavioural and environmental factors so as to identify those which influence health and diseases, using biostatistics and modelling.

In Southeast Asia, this discipline has made it possible to study the epidemiological system for influenza without being restricted to either that of animals or that of humans. Research has shown that certain influenza viruses affecting humans or birds, especially the pandemic influenza virus (H1N1pdm), are transmitted from humans to pigs, and then to other pigs. Since this animal can host human and avian viruses and recombine them, it could be the source of new highly pathogenic strains of influenza that are transmissible between human beings. Research associating veterinary epidemiologists and virologists and epidemiologists from the medical sector is beginning in order to improve detection systems for potentially pandemic strains in pig farms.

Surveillance systems are another vector for intersectoral synergies. Methods of disease monitoring and surveillance are being developed based on analysis and modelling of the ecology of pathogens or of epidemiological systems in time and space. In this sector too, research practices may be useful in implementing the One Health concept, provided they are assessed.

In Cambodia, for example, a project to monitor influenza viruses in animals and humans associates researchers (epidemiologists, virologists) and sectors (veterinary and medical), with the aim of pooling the resources available to human health services and livestock services, and of enhancing the efficiency of surveillance systems.

To offset the shortcomings of classical surveillance systems, which require considerable human and financial resources, participatory approaches are being implemented as alternative or complementary methods. In Southeast Asia, a new network, SEA-PREID (Participatory Research on Emerging Infectious Diseases in Southeast Asia), is fostering participatory epidemiology in order to optimise surveillance systems. It integrates different disciplines and sectors, and brings together livestock farmers, decision-makers and scientists.

Associations between sectors and between stakeholders need to be strengthened in order to combat zoonotic diseases. Control methods must also be optimised. In Cambodia, for example, veterinary and medical doctors are working on rabies, a major zoonose in Africa and Asia. In order to reduce the number and consequences of bites to humans, they are attempting to enhance methods to control canine populations in rural areas and to decentralise health care facilities.

\section{Disseminating principles and practices}

Not only do the research practices forge links between researchers from different disciplines and stakeholders from various sectors, but they also help to develop networks, monitoring centres, platforms and training programmes, which disseminate the principles of the One Health concept and facilitate its implementation and governance.

Five academic and veterinary research establishments from five Southeast Asian countries have worked along with CIRAD to create a research network in animal health and veterinary public health, GREASE (Management of Emerging Epidemiological Risks in Southeast Asia). By fostering synergies and sharing skills at the regional level, GREASE aims to improve the management of risks associated with transboundary and emerging diseases. Close links with the Institut Pasteur network, a key promoter and actor of the One Health initiative, are developing the connection with human health.

Certificate and in-house training courses are another tool, helping to build capacities and encouraging partnerships. An international postgraduate programme on the assessment and management of infectious risks at the human-animal-ecosystem interface (InterRisk) is currently being set up in Thailand. At the end of the course, graduates from the region will be able to integrate epidemiological, ecological, economic and risk management approaches.

In addition, professional training is given to physicians by veterinarians. CIRAD's veterinarians are thus training Chinese public health workers in the methods and principles of risk analysis. They take the methods used by veterinarians, such as decision trees, and adapt them to the needs of human public health. They study methods for the quantitative assessment of surveillance networks in animal health and human health, which can be adapted to future intersectoral systems for monitoring zoonotic diseases. 
A few words about..

François Roger is a veterinarian and epidemiologist at CIRAD, where he directs the AGIRs research unit (Animal and Integrated Risk Management http://ur-agirs.cirad.fr). After several years working in sub-Saharan Africa and in Europe, he developed research projects in Southeast Asia and launched a regional network (GREASE) aimed at connecting the different health sectors.

francois.roger@cirad.fr

\section{Towards one public health?}

Whether assessing the risks of emergence of a new human disease originating in wild or domestic animals, studying or controlling existing zoonoses, or coordinating sectors and stakeholders, research shows that it is possible and valuable to work together in a One Health perspective, and that these partnerships are prefiguring the application of this concept.
So why not use just one term: "public health"? Public health refers to the prevention of disease and the well-being of human societies. Veterinary public health covers actions concerning animals and their products aimed at protecting, preserving and improving human health and well-being. The One Health concept is working to achieve this.
This issue of Perspective is based on research in Africa and Asia by CIRAD researchers and $\mathrm{PhD}$ students: ecologists, veterinary epidemiologists and an anthropologist from the AGIRs research unit (Animal and Integrated Risk Management, http://ur-agirs.cirad.fr); socio-economists from the MOISA research unit (Markets, Organisations, Institutions and Stakeholder Strategies, http://umr-moisa.cirad.fr/) and the SELMET research unit (Mediterranean and Tropical Livestock Systems, http://umr-selmet.cirad.fr).

This research was conducted within the framework of the GREASE network (http://greasenetwork.com/) and the research platform Production and Conservation in Partnership (http://www.rp-pcp.org). It associated the following partners: Institut Pasteur International Network, IRD, CNRS, INP-ENVT (France); Centers for Disease Control and Prevention, EpiX Analytics (United States); Royal Veterinary College (University of London, United Kingdom); Murdoch University (Australia); Centre international de recherches médicales de Franceville (Gabon); University of Pretoria (South Africa); University of Hong Kong (China).

Several international agencies (FAO, OIE, WHO, ILRI) took part in the research; they have an important role to play in the implementation of One Health.

Articles published include:

Maganga G.D., Bourgarel M., Ebang Ella G., Drexler J.-F., Gonzalez J.-P., Drosten C., Leroy E.M., 2011. Is Marburg virus enzootic in Gabon? Journal of Infectious Diseases, 204: S800-S803.

Herbreteau V., Bordes F., Jittapalapong S., Supputamongkol Y., Morand S., 2012. Rodentborne diseases in Thailand: targeting rodent carriers and risky habitats. Infection Ecology and Epidemiology 2: 18637 - http://dx.doi. org/10.3402/iee.v2i0.18637

Abu Samra N., Thompson P. N., Jori F., Frean J., Poonsamy B., du Plessis D., Mogoye B. \& Xiao L., 2012. Genetic Characterization of
Cryptosporidium spp. in Diarrhoeic Children from Four Provinces in South Africa. Zoonoses Public Health, 20 Jun. DOI: 10.1111/j.18632378.2012.01507.x.

Trevennec K., Leger L., Lyazrhi F., Baudon E., Cheung C.Y., Roger F., Sriyal Peiris. J.-M., Garcia J.-M., 2011. Transmission of pandemic influenza H1N1 (2009) in Vietnamese swine in 2009-2010. Influenza Other Respi Viruses. 30 Dec. DOI: 10.1111/j.1750-2659.2011. 00324.x.

Rith S., Netrabukkana P., Sorn S., Mumford E., Mey C., Holl D., Goutard F., Bunthin Y., Fenwick S., Robertson I., Roger F., Buchy P., 2012. Serologic evidence of human influenza virus infections in swine populations, Cambodia. Influenza Other Respi Viruses. 30 May. DOI: 10.1111/j.1750-2659.2012.00382.x.

Peyre M., Zahhaf A., Figuié M., Binot A., Bonnet P., Goutard F., Roger F., 2011. Socioeconomical evaluation of surveillance systems for emerging animal diseases: merging veterinary and public health issues. First International One Health Congress, Melbourne, Australia, 14-16 February. EcoHealth 7, S8-S170.

Goutard F, Ponsich A., Ly S., Holl D., Allal L., Dab W., Roger F., Stärk K.D.C., 2012. “One Health" approach to quantitatively compare human and animal surveillance systems for avian influenza H5N1 in Cambodia. International Symposium on Veterinary Epidemiology and Economics (ISVEE), Maastricht, Netherlands, 20-24 August. Wageningen Academic Publishers.

Ponsich A., Goutard F., Sorn S., Tarantola A., 2012. A 6-months descriptive study of dog bites in rural Cambodia. Int J Infect Dis 2012; 16S1:57.027.

Among the training initiatives, the InterRisk postgraduate programme is being set up by the Faculty of Veterinary Medicine at Kasetsart University (Thailand) and the INP-ENVT (Institut national polytechnique de Toulouse - École nationale vétérinaire de Toulouse). 